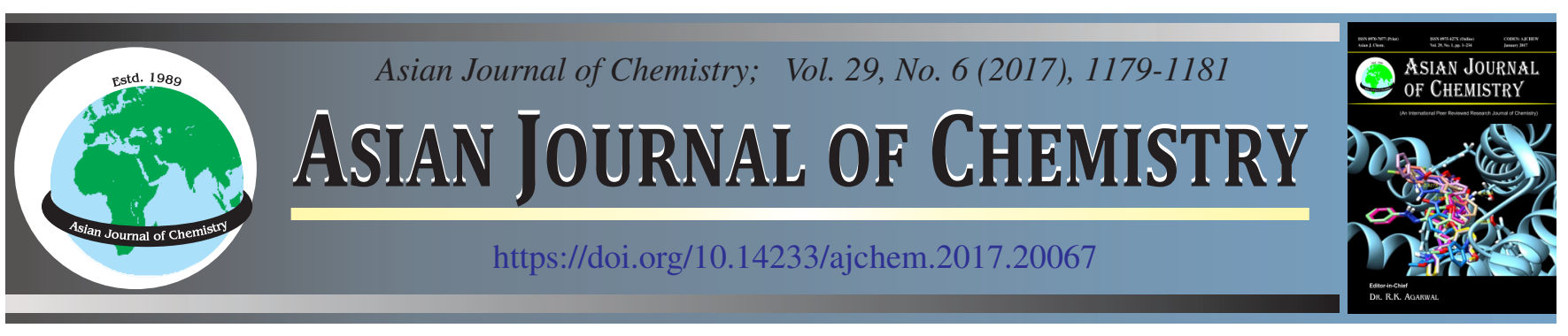

\title{
Comparison of Freeze Drying and Spray Drying for the Production of Anthrocyanin Encapsulated Powder from Jamun (Syzygium cumini)
}

\author{
ShWETHA and R. Preetha*
}

Department of Food Process Engineering, SRM University, Kattamukulathur-603 203, India

*Corresponding author: E-mail: preetha.r@ktr.srmuniv.ac.in

Received: 5 May 2016;

Accepted: 10 February 2017;

Published online: 10 April 2017;

AJC-18322

\begin{abstract}
The extracts of jamun which has a high anthocyanin content $(125.02 \mathrm{mg} / 100 \mathrm{~g})$ were spray dried and freeze dried using maltodextrins and gum arabia as a carrier and coating agents in 1:1, 1:2 and 1:4 cores to wall ratio for spray drying and 1:2 and 1:4 ratios for freeze drying technique respectively. Higher inlet/outlet air temperatures caused greater anthocyanin loss during spray drying when compared to freeze dried powder. The quality attributes of the powders which were produced at optimum drying temperatures $\left(110^{\circ} \mathrm{C}\right)$ were characterized by their anthocyanin content, encapsulation efficiency and colour. The above analysis was performed for eight weeks duration. Scanning electron microscope was used to study the morphology and size of the powders. For determination the stability of microencapsulated pigments, samples were stored in amber bottle under different storage temperatures $\left(4{ }^{\circ} \mathrm{C}\right.$ and $\left.32{ }^{\circ} \mathrm{C}\right)$. The results showed that the encapsulated jamun (Syzygium cumini) powder is a promising natural colourant for food applications.
\end{abstract}

Keywords: Syzygium cumini, Anthocyanin, Encapsulated pigment content, Colour stability.

\section{INTRODUCTION}

One of the important attributes in food acceptance is colour which gives the quality appearance since things are perceived based on sensory evaluation [1]. Anthocyanin are natural watersoluble pigment responsible for all the pink, magneta, red, violet and blue colours in the petals, leaves and fruits of higher plants. Syzygium cumini commonly know as black plum and jamun in Hindi, belongs to a family Myrtaceae. It is a tropical fruit crop grown mostly in India and Indonesia. Anthocyanins have shown antagonistic activity to some bacteria, virus and fungi and also protect food from microbial spoilage [2].

The diversity of anthocyanins is not only the different colours they can produce, but also the wide array of plant materials that they are found in including leaves, fruits, flower and roots. The word anthocyanin is itself a combination of the Greek words for blue and flower [3]. The incorporation of anthocyanin into the food systems not only increases the colour intensity but also increases the medicinal and therapeutic values of the food products.

Food drying may be performed in different drying methods in which their economical factors, initial properties and final desired characteristics of the product [1]. Freeze drying technique is based on the water removal by sublimation which is used to obtain several industrial products [4]. Here substances are not exposed to high temperatures, so the freeze- dried product preserves their initial nutritious characteristics. The product retains its original quality, shape and texture instantaneously with long shelf life. On the other hand, spray drying technique consist of maximum heat transfer which could be referred to product with liquid- like behaviour [1]. Their efficiency and speed spray drying technique makes them the most used technique for food and biological materials [4-6].

Water removal in this process is faster and quality of the product is fine with good texture and moreover rehydration is quick $[1,7]$. Since then the pigment extracted is liquid in nature and it's feasible to work with both drying technique for it to be preserved without damaging the nature of the pigment and to bring the natural quality sustained its encapsulation efficiency.

The aim of this research was to investigate the effects of using freeze and spray drying to obtain encapsulated pigment powder on the product characteristics (composition, stability and colour).

\section{EXPERIMENTAL}

Freshly harvested jamun fruits (Syzygium cumini) with similar maturity and weight were used to raw materials and they were procured from the local vendors in Chennai, India and washed and finally stored at $4{ }^{\circ} \mathrm{C}$ prior to the experiments. 
Microencapsulation by freeze drier: Arabic gum and maltodextrin, in the ratio of 1:1 (w/w), were hydrated in 200 $\mathrm{mL}$ of water at $60{ }^{\circ} \mathrm{C}$ under stirring. The sample was dried using vacuum freeze dryer (Lyodol, India) extract was added to the solution of encapsulating agents, in the ratio of 1:4 (colouring:encapsulant) (w/w) and homogenized in a mechanical stirrer at $1200 \mathrm{rpm}$ for $30 \mathrm{~min}$ until the temperature reached $20^{\circ} \mathrm{C}$. The mixture was stored in freezer and subjected to drying in freeze drier for $60 \mathrm{~h}$ (Table-1).

Microencapsulation by spray drier: Spray drying was carried out in the spray dryer machine (SM Science Tech, India). The dryer was operated at an inlet temperature of 110 ${ }^{\circ} \mathrm{C}$ and outlet temperature of $75-65{ }^{\circ} \mathrm{C}$ at a flow rate of 100 $\mathrm{mL} / \mathrm{h}$.

Encapsulation efficiency: The encapsulation efficiency was calculated from total anthocyanin content as the ratio of the inside anthocyanin content to the total anthocyanin content after drying [8].

where the surface anthocyanin content is the quantity of compound around the encapsulating powder.

Encapsulation efficiency $(\%)=[($ Total anthocyanin content in jamun extract - Anthocyanin content after encapsulation)/

Total anthocyanin content in jamun extract] $\times 100$

Morphology and particle size: Scanning electron microscopy (JES-FA200) images were used to examine the shape and surface morphology of the dried encapsulated jamun powder. Sample was placed on the aluminum stub prior to the placing them in a sputtering device for $15 \mathrm{~min}$ at $15 \mathrm{~mA}$. The dried sample was examined under the SEM.

Colour analysis: The colour of the fresh juice and reconstituted samples was analyzed using Hunter colourimeter (Color Quest XE) for measuring colour and the difference in their colour parameters was calculated and the Hunter values (L, a, b) the optical parameters were compared. $2 \mathrm{~g}$ of powder was dissolved in approximately $20 \mathrm{~mL}$ of distilled water and centrifuged at $4000 \mathrm{rpm}$ for $15 \mathrm{~min}$ and the colour of the supernatant was measured. All the measurements were recorded for each sample and their mean values calculated. The colour values represented whiteness or brightness/darkness (L), redness/greenness (a) and yellowness/blueness (b). Another informative colour attribute in the production of powder is the total colour difference (TCD) which is a combination of parameters $\mathrm{L}$, $\mathrm{a}$ and $\mathrm{b}[9,10]$, total colour difference is a colourimetric parameter commonly used to characterize the variation of colour in foods during processing and is calculated.

Pigment stability: The stability of the pigments was tested in extracts of anthocyanin at different temperatures, $\mathrm{pH}$ and light. The $\mathrm{pH}$ of the extracts was adjusted with $\mathrm{HCl}$ and $\mathrm{NaOH}$ $1 \mathrm{~N}$; glass flasks were used for storage, each containing $10 \mathrm{~mL}$ of the extract; absorbance was determined to these extracts every 7 days for a period of 8 weeks. The experiment was performed in duplicate. Checking the anthocyanin content by spectrophotometer (Jasco, V-730) to know the stability of the pigment after encapsulation.

\section{RESULTS AND DISCUSSION}

Microencapsulation and encapsulation efficiency: In this study, both drying methods were successfully managed to dry the aqueous extract and the physical properties of the dried extract was maintained. The microcapsules studied have microencapsulation efficiency (\% EM) of $98.12 \%$ in spray dried powder and freeze dried showing $97.88 \%$ as shown in Table-2. This result was very close to that reported by Barbosa and Mercadante [11], who had a microencapsulation efficiency of bixin microencapsulated in maltodextrin and arabic gum (1:1) of $81 \%$, using bixin from annatto seeds extracted.

Morphology and particle size: The freeze dried powders were in the form of flakes which took longer drying period around $60 \mathrm{~h}$ (Fig. 1a). On the other hand, spray drying process produced fine particle (Fig. 1b) that shows the decrease in the particle size was the result of an increase in the energy available for atomization. Higher frequency will produce smaller droplets, hence smaller particle size and more uniformly distributed [7].
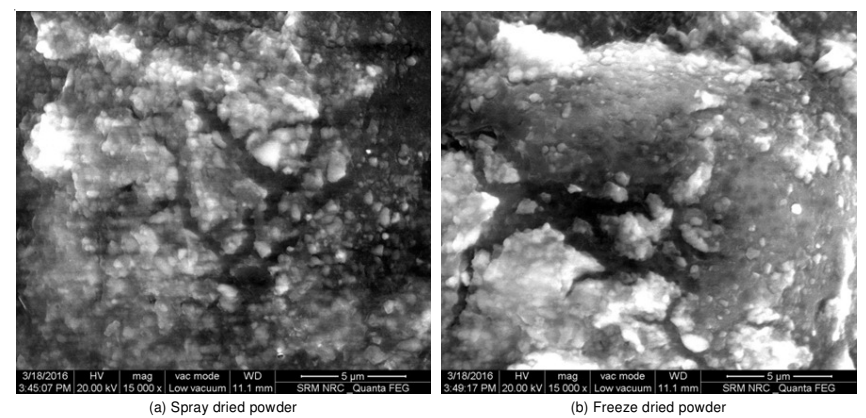

Fig. 1. Scanning electron microscope images $(\times 15000$ magnification $)$ of microcapsules having GA:MD ratio of 1:4 and core to coating ratio of $1: 2$ prepared and dried by spray drying and freeze drying

\begin{tabular}{ccccccccc}
\multicolumn{8}{c}{ TABLE-1 } \\
\hline $\begin{array}{c}\text { Trail ratios } \\
\text { (M/A.G.) }\end{array}$ & $\begin{array}{c}\text { Inlet } \\
\text { temperature } \\
\left({ }^{\circ} \mathrm{C}\right)\end{array}$ & $\begin{array}{c}\text { Outlet } \\
\text { temperature } \\
\left({ }^{\circ} \mathrm{C}\right)\end{array}$ & $\begin{array}{c}\text { Inlet feed } \\
\text { flow rate }\end{array}$ & $\begin{array}{c}\text { Concentration } \\
\text { of maltodextrin } \\
(\mathrm{g})\end{array}$ & $\begin{array}{c}\text { Concentration } \\
\text { of gum arabia } \\
(\mathrm{g})\end{array}$ & $\begin{array}{c}\text { Volume of } \\
\text { extract }(\mathrm{mL})\end{array}$ & $\begin{array}{c}\text { Volume of wall } \\
\text { material }(\mathrm{mL})\end{array}$ & $\begin{array}{c}\text { Total feed } \\
\text { volume }(\mathrm{mL})\end{array}$ \\
\hline $1: 4$ & 110 & 75 & 15 & $70 \%$ & 20 & 100 & 400 & 500 \\
$1: 2$ & 110 & 70 & 20 & $40 \%$ & 20 & 100 & 200 & 300 \\
$1: 1$ & 110 & 65 & 15 & $20 \%$ & 20 & 100 & 100 & 200 \\
\hline M = Maltodextrin; A.G. Arabic gum
\end{tabular}

TABLE-2

ENCAPSULATION EFFICIENCY SHOWN FOR SPRAY DRIED AND FREEZE DRIED POWDER

\begin{tabular}{cccc|cc}
\hline & \multicolumn{3}{c}{ Spray dried powder } & \multicolumn{2}{c}{ Freeze dried powder } \\
\hline Composition of wall material & $1: 4$ & $1: 2$ & $1: 1$ & $1: 4$ & $1: 2$ \\
Encapsulation efficiency (\%) & 98.12 & 97.87 & 97.82 & 97.88 & 97.85 \\
\hline
\end{tabular}


TABLE-3

ANTHOCYANIN CONTENT VARYING AFTER EACH WEEK DURATION FOR FREEZE DRIED POWDER ON STORAGE

\begin{tabular}{cccccccccc}
\hline Ratios & Initial & Week 1 & Week 2 & Week 3 & Week 4 & Week 5 & Week 6 & Week 7 & Week 8 \\
\hline $1: 4$ & $0.1660 \pm$ & $0.1517 \pm$ & $0.1476 \pm$ & $0.1242 \pm$ & $0.1080 \pm$ & $0.097 \pm$ & $0.0825 \pm$ & $0.0894 \pm$ & $0.0756 \pm$ \\
& 0.00242 & 0.00125 & 0.00153 & 0.00205 & 0.0059 & 0.00278 & 0.00286 & 0.00205 & 0.00205 \\
$1: 2$ & $0.1590 \pm$ & $0.1476 \pm$ & $0.1461 \pm$ & $0.1219 \pm$ & $0.0990 \pm$ & $0.087 \pm$ & $0.0811 \pm$ & $0.0754 \pm$ & $0.0703 \pm$ \\
& 0.0025 & 0.00153 & 0.00148 & 0.00216 & 0.00263 & 0.0015 & 0.0012 & 0.00205 & 0.0017 \\
\hline
\end{tabular}

TABLE-4

ANTHOCYANIN CONTENT VARYING AFTER EACH WEEK DURATION FOR SPRAY DRIED POWDER ON STORAGE

\begin{tabular}{ccccccccccc}
\hline Ratios & Initial & Week 1 & Week 2 & Week 3 & Week 4 & Week 5 & Week 6 & Week 7 & Week 8 \\
\hline $1: 4$ & $0.1537 \pm$ & $0.1528 \pm$ & $0.1517 \pm$ & $0.1452 \pm$ & $0.1401 \pm$ & $0.1224 \pm$ & $0.1047 \pm$ & $0.0923 \pm$ & $0.0905 \pm$ \\
& 0.00258 & 0.0021 & 0.0019 & 0.0017 & 0.00156 & 0.00156 & 0.00163 & 0.00205 & 0.0016 \\
$1: 2$ & $0.1479 \pm$ & $0.1423 \pm$ & $0.1387 \pm$ & $0.1342 \pm$ & $0.1297 \pm$ & $0.1241 \pm$ & $0.1129 \pm$ & $0.1057 \pm$ & $0.081 \pm$ \\
& 0.00125 & 0.00205 & 0.00163 & 0.00125 & 0.00163 & 0.0156 & 0.0017 & 0.00163 & 0.00509 \\
$1: 1$ & $0.1428 \pm$ & $0.1412 \pm$ & $0.1382 \pm$ & $0.1336 \pm$ & $0.1316 \pm$ & $0.1287 \pm$ & $0.1184 \pm$ & $0.1048 \pm$ & $0.098 \pm$ \\
& 0.00125 & 0.00205 & 0.0016 & 0.00125 & 0.00125 & 0.00205 & 0.00216 & 0.0024 & 0.00289 \\
\hline
\end{tabular}

Colour analysis: Generally, the colour degradation occurs in two distinct periods: during the initial period, the degradation rate is very fast, up to about 4 to 6 weeks and the second period the degradation rate is slow [12]. In present study, the pigment degradation was observed after 60 days, namely after 5th week showing period of degradation, where the decolouration was rapid. The change in colour and degradation of pigment are the reason for the stability changes after 5 th week, there dimensions changes were run to know there was significant $(\mathrm{p}<$ $0.05)$ for all 5 weeks.

Stability of anthocyanin pigments: The behaviour of anthocyanin extracts under different storage conditions was decreased during the 1 st week and then remain more stable for 4 weeks of storage, finding no significant difference between the samples stored at $4{ }^{\circ} \mathrm{C}$ both in the presence and absence of light (Table-3). At $32{ }^{\circ} \mathrm{C}$, in the absence of light, the samples displayed similar values to those stored at $4{ }^{\circ} \mathrm{C}$ from the 4 th week. These three extracts were the ones which retained more pigment compared to the others (Table-4). The extracts kept at varying temperatures in the presence and absence of light at $32{ }^{\circ} \mathrm{C}$, a considerable decrease of absorbance occurred after 5 th week, however no significant differences for samples stored at $4{ }^{\circ} \mathrm{C}$.

\section{Conclusion}

The effects of different encapsulation parameters on the properties of encapsulated powder were studied. The wall material and inlet temperature affected the moisture content, total anthocyanin content, encapsulation yield, encapsulation efficiency and size of encapsulated powder. Compare to freeze dried powder spray dried powder with gum Arabia and maltodextrine as the wall material (1:4 wall to core combination) gave the highest encapsulation efficiency, low moisture content and homogeneous particle size distribution of powder. Higher temperature gave lower moisture content powder. So the suitable conditions for encapsulation were using spray drying since there is less drying period when compared to freeze dried powder with better colour stability during storage studies. Storage at $4{ }^{\circ} \mathrm{C}$ increased half-life of spray dried anthocyanin pigments three times compared to 32 temperature.

\section{ACKNOWLEDGEMENTS}

Since thanks to Dr. M. Vairamani and Dr. Athma Selvi, SRM University, for all support and facilities.

\section{REFERENCES}

1. R. Baruffaldi and M.N. Oliveira, Fundamentos da technologia de alimentos, vol. 3, p. 317 (1998).

2. P. Chattopadhyay, S. Chatterjee and S.K. Sen, Afr. J. Biotechnol., 7, 2972 (2008).

3. F. Delgado-Vargas and O. Paredes-Lopez, Anthocyanins and Betalains, In: Natural Colorants for Food and Nutraceutical Uses, CRC Press, Boca Raton, pp. 167-191 (2003).

4. A. Ciurzyñska and A. Lenart, Pol. J. Food Nutr. Sci., 61, 165 (2011); https://doi.org/10.2478/v10222-011-0017-5.

5. S.S. Costa, B.A.S. Machado, A.R. Martin, F. Bagnara, S.A. Ragadalli and A.R.C. Alves, Afr. J. Food Sci., 9, 462 (2015); https://doi.org/10.5897/AJFS2015.1279.

6. Labmaq Do Brasil Ltd., Spray Dryer Operations Manual MSD 5.0, Department of Engineering, p. 65 (2010).

7. M.F. Zotarelli, B.D.A. Porciuncula and J.B. Laurindo, J. Food Eng., 108, 523 (2012); https://doi.org/10.1016/i.jfoodeng.2011.09.014.

8. E.I. Paramera, S.J. Konteles and V.T. Karathanos, Food Chem., 125, 892 (2011);

https://doi.org/10.1016/j.foodchem.2010.09.063.

9. M. Maskan, J. Food Eng., 72, 218 (2006); https://doi.org/10.1016/j.jfoodeng.2004.11.012.

10. H. Mirsaeedghazi, Z. Emam-Djomeh and S.M. Mousavi, J. Food Sci. Technol., 46, 538 (2009).

11. M.M.J. Barbosa and A.Z. Mercadante, Tecnologia \& Ciencia Agropecuária, 2, 23 (2008).

12. M.E. Rodríduez-Huezo, R. Pedroza-Islas, L.A. Prado-Barragán, C.I. Beristain and E.J. Vernon-Carter, J. Food Sci., 69, 351 (2004); https://doi.org/10.1111/j.1365-2621.2004.tb13641.x. 